\title{
Plummer Vinson Syndrome: First Two Tunisian Pediatric Cases
}

\author{
Werdani A*, Jammeli N, Rassas A, Boussoffara R and Mahjoub B \\ Department of Pediatrics, Taher Sfar Teaching Hospital, Tunisia
}

\begin{abstract}
Background: Plummer Vinson syndrome is a rare cause of dysphagia in children. It associates an oesophageal organic stenosis to a sideropenic anemia.

Case Reports: Two Tunisian boys aged respectively 14 and 9 years-old were admitted to investigate dysphagia for solid foods. The adolescent patient was a black and he suffers from food blocking since 2 years ago. The assessment revealed a sideropenic anemia due to intestinal giardiasis. While the second patient was followed for a chronic anemia since he was 3 years old. For both of them, the swallow barium exploration showed an annular stenosis of the cervical esophagus mimicking "a thread knotted on a round tube" related to a circular web identified by fibroscopy. The iron supplementation and dilatation by the esophagoscope allowed the resolution of the clinical signs.
\end{abstract}

Conclusion: Plummer Vinson syndrome exists in paediatric population. It should be evoked in any children presenting with upper dysphagia for solid foods in order to initiate iron supplementation and to watch for cancerous degeneration by regular followup.

KEYWORDS: Plummer vinson; Dysphagia; Oesophageal stenosis; Anemia; Children

\section{INTRODUCTION}

Plummer Vinson syndrome (PVS), also called Brown-Kelly, Paterson syndrome or "sideropenic dysphagia" is defined by an acquired dysphagia due to web or webs in the post cricoid oesophagus associated to an iron deficiency [1-3].

It is a rare entity that affects especially females from white race around the third and the fifth decades [3]. Before that age, PVS is uncommon [1]. Few cases of PVS in pediatric population were reported in literature [1].

Its pathogenesis remains unclear [3]. Classically, it is a curable disease by iron treatment and esophagus dilatation [4].

However, several questions are raised in relation with its unclear pathogenesis and its long-term outcome in children. Thus, its scarcity incites us to report two new Tunisian cases.

\section{CASE REPORTS}

\section{Case 1}

We report the case of a black 14 years-old adolescent, without a previous pathological history, admitted to the pediatric department of Taher Sfar teaching hospital in Mahdia, Tunisia, seeing he was suffering from dysphagia. He experienced, intermittent with progressive worsening, solid food impactions for two years, so that he was forced to restrict his diet to liquid or mixed food causing a weight loss. At clinical examination, pale conjunctiva and a skinned tongue were noted. Esophagus and gastrointestinal barium radiological investigation showed, at the frontal incidence (Figure 1), an annular stenosis of the cervical esophagus at the level of $\mathrm{C} 5$, mimicking "a thread knotted on a round tube". The lateral incidence showed two layered indentations located on the anterior and the posterior esophageal walls (Figure 1). Upper endoscopy objectified an annular web located at $17 \mathrm{~cm}$ from dental arches.
Quick Response Code:

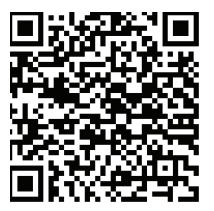

Address for correspondence: Werdani Amina, Adress: Pediatrics Department, Taher Sfar Teaching Hospital, Tunisia

Received: September 18, $2021 \quad$ Published: October 07, 2021

How to cite this article: Werdani A, Jammeli N, Rassas A, Boussoffara R, Mahjoub B. Plummer Vinson Syndrome: First Two Tunisian Pediatric Cases. 2021- 3(5) OAJBS.ID.000329. DOI: 10.38125/OAJBS.000329 
It induced an important luminal reduction of the esophagus that the endoscope may pass. Complete blood count (CBC) showed a hypochromic microcytic anemia (hemoglobin: $5.4 \mathrm{~g} / \mathrm{dl}$ ) with low level of iron (4.6 ug/l, normal value: $30-90 \mathrm{ng} / \mathrm{l}$ ). This anemia was due to intestinal Giardiasis found at the anatomopathological analysis of the duodenal mucosa. PVS diagnosis was made, and the patient treated by a daily iron supplementation in the dose of $5 \mathrm{mg} /$ $\mathrm{kg}$ /day for three months. He also received metronidazole (30mg/ $\mathrm{kg}$ /day) during seven days for his Giardiasis. The outcome was satisfying; dysphagia recovery and weight gaining were obtained in one month. Three months later, his hemoglobin was normal, and he did not show new relapses of the disease. After a follow up of 5 years, the child is asymptomatic.

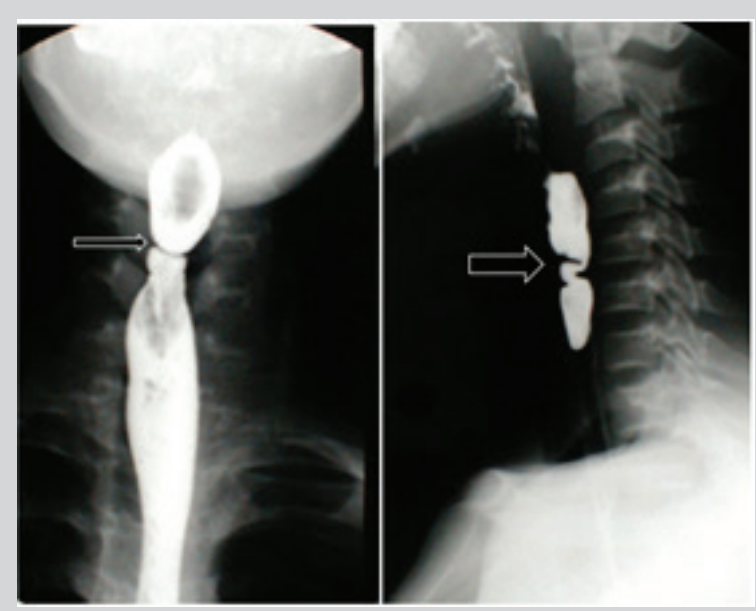

Figure 1: Esophagus gastrointestinal Barium swallow:

(a) Frontal Incidence: Annular stenosis of the cervical esophagus like a "thread knotted on a round tube" (Thin arrow).

(b) Lateral Incidence: Layered indentations on the anterior and posterior esophagus wall (Thick arrow).

\section{Case 2}

It is about a child referred to the pediatric department of Taher Sfar teaching hospital in Mahdia to investigate a pallor noticed by his parents at the age of 3 years. Investigations showed microcytic and hypochromic anemia (hemoglobin: $5.8 \mathrm{~g} / \mathrm{dl}$, mean corpuscular volume (MCV): $48.1 \mathrm{fl}$, mean corpuscular hemoglobin content (MCHC):13 pg/l) with iron deficiency (iron level: 1.7 umol/l). The child was treated as a martial deficiency anemia. He received iron supplementation at a dose of $10 \mathrm{mg} / \mathrm{kg} /$ day. CBC performed one week after the start of martial therapy showed reticulocytes at 248 $000 / \mathrm{mm} 3$. The outcome was marked by the persistence of a low ferritinemia at $4.7 \mathrm{ug} / \mathrm{l}$ despite good adherence to treatment. Other investigations were made, namely, hemoglobin electrophoresis and coeliac serology; both were normal. At the age of 9 years old, he developed an upper solid dysphagia. Physical examination showed conjunctival pallor, angular cheilitis and glossitis. The CBC showed a deep regenerative hypochromic and microcytic anemia at $6 \mathrm{~g} /$ $\mathrm{dl}, \mathrm{MCV}$ at $54.3 \mathrm{fl}, \mathrm{MCHC}$ at $13.5 \mathrm{pg} / \mathrm{l}$ and reticulocytes at $133000 /$ $\mathrm{mm} 3$. Esophagus and gastrointestinal barium swallow (Figure 2) showed an annular stenosis of the cervical esophagus at the level of C6 with dilatation of the upstream portion. The diagnosis of PVS was confirmed by the upper gastrointestinal fibroscopy showing an esophageal diaphragm $20 \mathrm{~cm}$ from dental arch that could be crossed by the endoscope. The downstream segment was normal. Esophageal endoscopy improved the symptoms and disappeared the dysphagia, iron supplementation was prescribed for 3 months. At the follow-up, the patient had a normal martial assessment.

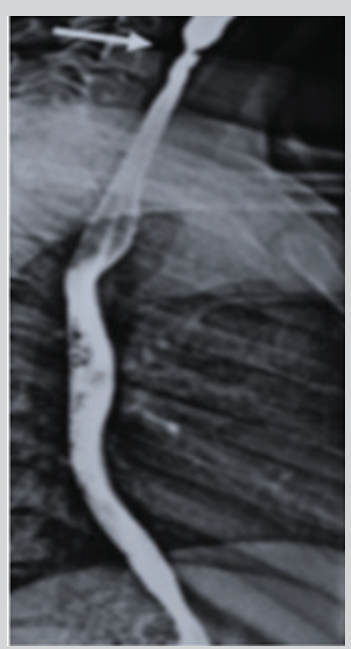

Figure 2: Lateral incidence of esophagus gastrointestinal barium swallow: Annular stenosis at the level of C6 (Arrow) and dilatation of the upper portion of the esophagus. 


\section{DISCUSSION}

Dysphagia is a rare symptom in children that often reveal a serious disease such as PVS. This entity is more common in adult females while pediatric cases around the world are rare. First pediatric cases were reported by Crawford and al in 1965 [5]. In this manuscript we report the 2 first pediatric Maghreb cases deriving from Tunisia. Nineteen children with PVS were reported in le literature in 13 publications [1,4-15].

We resumed their epidemiological, clinical, investigations, treatment and outcome in the Table 1 . They were 10 boys and 9 girls with a mean age of 10 years ranging from 1.5 to 18 years old. Twelve among 19 patients were aged more than 10 years old.

Table 1: Epidemiological, clinical, investigations, treatment and outcome of the 19 pediatric PVS reported in the literature $[1,4-15]$.

\begin{tabular}{|c|c|c|}
\hline \multirow{2}{*}{ Gender } & Male & $10 / 19$ \\
\hline & Female & $9 / 19$ \\
\hline Mean Age & & 10 years \\
\hline \multirow{5}{*}{ Clinical Presentation } & Progressive solid dysphagia & $12 / 19$ \\
\hline & $\begin{array}{c}\text { Brutal solid dysphagia with } \\
\text { sialorrhea }\end{array}$ & $1 / 19$ \\
\hline & Food blocking/impaction & $6 / 19$ \\
\hline & Frequent choking & $3 / 19$ \\
\hline & Recurrent vomiting & $2 / 19$ \\
\hline Diagnostic Delay & & 3 months - 5 years \\
\hline Anemia & & $18 / 19$ \\
\hline Iron deficiency & & $19 / 19$ \\
\hline \multirow{2}{*}{ Barium swallow } & & Esophagus web: $18 / 19$ \\
\hline & & Normal: 1 case ( 1.5 years) \\
\hline \multirow{3}{*}{ Endoscopic Diagnosis } & & Not performed: $2 / 19$ \\
\hline & & Not available: $3 / 19$ \\
\hline & & Annular esophagus stenosis: $14 / 19$ \\
\hline \multirow{4}{*}{ Iron therapy } & & Oral: $13 / 19$ \\
\hline & & Intravenous: $3 / 19$ \\
\hline & & Oral + Intravenous: $1 / 19$ \\
\hline & & Transfusion of red blood cells: $2 / 19$ cases \\
\hline \multirow{2}{*}{ Endoscopic Dilatation } & & 19-Oct \\
\hline & & Asymptomatic after the first treatment: $12 / 19$ \\
\hline \multirow{3}{*}{ Outcome } & & Partial resolution of dysphagia requiring further dilatations: $3 / 19$ \\
\hline & & Retarded resolution without further endoscopic dilatation: 3/19 \\
\hline & & Protein loss enteropathy: 1 case (for 1 year after first treatment) \\
\hline
\end{tabular}

This disease is probably more common in the black African children than in the white one, among the two patients we reported there was a black child too. In addition of symptoms of iron deficiency, PVS gives a triad; namely dysphagia, anemia by martial deficiency and upper esophageal webs [16]. Dysphagia is usually progressive and with solids rather than liquids [5,13]. Frequent choking, recurrent vomiting, blocking food have also been reported $[1,4,12]$. Berthé $[15]$ published a brutal dysphagia with sialorrhea in a 14-year-old adolescent, he had a foreign body embedded by a stenotic esophageal web. In adults, incidental finding, association with auto immune diseases and severe presentations such as hydrops have been reported $[15,17]$. The pathogenesis of the disease remains unclear and is a subject of debate [18]. the esophageal lesion raises a problem of cause and effect. Indeed, in one of our patients, the martial deficiency was not corrected by the simple martial treatment given in the long term. However, a rapid improvement was observed after the digestive endoscopy and the crossing of the stenosis. Authors proposed several risk factors such as genetic predisposition, nutritional deficiencies and autoimmunity $[11,15,19]$. But the most incriminating factor in VPS is chronic martial deficiency leading to peristalsis and anatomic abnormalities [18]. Low ferritinemia is constant compared to low level of hemoglobin [15]. Diagnosis is facilitated thanks to the barium swallow test showing a regular and annular stenosis of the cervical esophagus mimicking a thread knotted on a round tube on the frontal incidence and layered indentations corresponding to esophagus webs on the lateral incidence [1]. Esophagoscopy has a double interest; on the one hand to confirm the diagnosis showing a narrowed lumen of the esophagus by annular webs and on the other hand to relieve the dysphagia by dilating the stenosis [11]. It is to be noted that esophageal biopsy is not essential for diagnosis. Treatment based on oral iron supplementation is often sufficient and endoscopic dilatation is not necessarily required $[7,12]$. Nevertheless, dilatation therapy is an effective alternative when the stenosis cannot be crossed by the endoscope [3]. Outcome is often good, and the esophagus lesion is reversible [20]. However, authors evoke PVS as a risk factor for hypo pharyngeal carcinoma in black children [14,21]. Nadiaye and al reported 15 children with squamous carcinoma of the hypopharynx. PVS was noted in $86.7 \%$ of these cases suggesting the role of PVS in carcinomatous 
degeneration [22]. According to this publication, the number of 19 pediatric PVS recorded on the basis of literature would be surely underestimated.

\section{CONCLUSION}

Plummer Vinson syndrome is rarely described in Africa. Extensive carrying out of upper digestive endoscopy in the face of iron deficiency anemia which cannot be corrected despite proper iron treatment would allow a new approach to its prevalence. Dysphagia is the main symptom that can reveal the Plummer Vinson syndrome. Endoscopic dilation is a procedure of choice in the treatment of oesophageal diaphragms during this syndrome. The risk of degeneration requires regular endoscopic monitoring.

\section{REFERENCES}

1. Butori M (2015) Plummer-vinson syndrome in children. J Pediatr Gastroenterol Nutr 61(5): 547-552.

2. Atmatzidis K (2003) Plummer-vinson syndrome. Dis Esophagus 16(2): 154-157.

3. Fikret D, Necip K, Vahap O, Mehmet Y, Mehmet B, et al. (2005) Plummervinson syndrome and dilation therapy: a report of two cases. Turk J Gastroenterol 16: 224-227.

4. Crawfurd MA (1965) Paterson-kelly syndrome in adolescence: A report of five cases. 1(5436): 693.

5. Ganesh RL, Janakiraman MJA, Sathiyasekaran OTP (2008) Plummervinson syndrome: An unusual cause of dysphagia. 28(2): 143-147.

6. Puntis J (1989) Dysphagia due to oesophageal web. Arch Dis Child 64(1): 141-143.

7. Diagne I (1988) Kelly-paterson, plummer-vinson syndrome or sideropenic dysphagia apropos of a case in a child. Dakar Med 33(1-4): $1-3$

8. Seitz ML, Sabatino DJJAH (1991) Plummer-vinson syndrome in an adolescent. J Pediatr Gastroenterol Nutr 12(3): 279-281.
9. Mansell N (1999) Plummer-vinson syndrome: A rare presentation in a child. J Laryngol Otol 113(5): 475-476.

10. Dinler G (2009) Plummer-vinson syndrome in a 15-year-old boy. Turk J Pediatr 51: 384-386.

11. Anthony R (1999) A case of plummer vinson syndrome in childhood. J Pediatr Surg 34(10): 1570-1572.

12. Rodríguez MJL (2002) Sideropenic dysphagia in an adolescent. J Pediatr Gastroenterol Nutr 34(1): 87-90.

13. Hartfield DS (2010) Reversible sideropenic dysphagia in a toddler with iron deficiency. Clin Pediatr 49(2): 180-182.

14. De Blavous C (2015) P-398-Dysphagie aux solides et anémie: le syndrome de Plummer Vinson. 5(22): 334.

15. Berthé A (2014) Unusual presentations of plummer vinson syndrome in black African: Report of two cases. Pan Afr Med J 19: 145.

16. Gültepe İ, Başaranoğlu M (2016) Two cases with plummer-vinson syndrome in the $21^{\text {st }}$ century. Turk J Gastroenterol 27(1): 81-82.

17. Atig A (2010) Syndrome de Plummer-Vinson révélé par un tableau d'anasarque: à propos d'un cas. 2010(31): S103.

18. Ali SN. Association of Iron Deficiency with Dysphagia.

19. Dickey W, McConnell (1999) Celiac disease presenting as the patersonbrown kelly (Plummer-vinson) syndrome. Am J Gastroenterol 94(2): 527-529.

20. Bakshi SB (2015) Plummer vinson syndrome-is it common in males? Arq Gastroenterol 52(3): 250-252.

21. Köksal Y (2005) Hypopharyngeal squamous cell carcinoma in a child. Int J Pediatr Otorhinolaryngol 69(7): 989-991.

22. Ndiaye I (2009) Squamous carcinoma of the hypopharynx in children in Senegal: Between disarray and enigma. Int J Pediatr Otorhinolaryngol 73(3): 357-361. 